\title{
ĐÀO TẠO ĐÁP ỨNG NHU CẦU XÃ HỘI VÀ HỘI NHẬP QUỐC TẾ TIẾP CẬN CDIO TRONG CÁC TRƯỜNG ĐẠI HỌC ĐA NGÀNH ĐỊNH HƯỚNG NGHIÊN CỨU
}

\author{
Tăng Văn Lâm ${ }^{(*)}$, Vũ Kim Diến ${ }^{(* *)}$ \\ (*) Tiến sĩ. Truoòng Đại học Mỏ - Địa chất. Email: lamvantang@gmail.com. \\ (**)Thạc sĩ. Trường Cao đẳng Công nghiệp và Xây dựng. \\ DOI: $10.37550 / \mathrm{tdmu} . \mathrm{CFR} / 2021.01 .107$
}

\section{Tóm tắt}

Rà soát, xây dụng và phát triển chuoong trình đào tạo theo tiếp cận CDIO trong giáo dục đại học hiện nay là một trong các hướng đi tất yếu trong bối cảnh cuộc cách mạng công nghiệp 4.0 đang diễn ra mạnh mẽ trên khắp thế giới. Trên con đường họi nhập để phát triển, Đại học Mỏ - Địa chất là một trong các trường đại học đã và đang xây dụng chưong trình đào tạo theo tiếp cận CDIO. Trong bài báo này xin được trình bày nhũng kết quả ban đầu trong quá trình, ra soát, điều chỉnh và xây dưng chuoong trình đào tạo theo tiếp cận CDIO và chuẩn quốc tế trên cơ sở điều kiện vật chất hiện có của Nhà truòng. Hy vọng rằng kết quả của bài báo sẽ đóng góp một phần nhỏ vào tiến trình thưc hiện được muc tiêu là triển khai phương pháp đào tạo: Hình thành ý twởng - Thiết kế - Triển khai Vận hành trong các Trường Đại học đa ngành định huớng nghiên cứu.

Từ khóa: chuẩn đầu ra, chuẩn kiến thức kỹ năng, mô hình CDIO, ngườ học

\section{1. Đặt vấn đề}

Sự hội nhập của Việt Nam vào nền kinh tế toàn cầu hiện nay đã đặt ra nhiều yêu cầu ngày càng lớn hơn đối với cơ sở giáo dục (GD) đại học $(\mathrm{ĐH})$ Việt Nam. Cuộc cách mạng công nghiệp lần thứ tư hay còn gọi là cuộc cách mạng số diễn ra từ đầu thế kỷ 21 ở các nước phát triển trên thế giới và đang có ảnh hưởng rất lớn đến Việt Nam. Đặc trưng của cuộc cách mạng công nghiệp lần này là sẽ ngày càng phổ biến trí thông minh nhân tạo và máy móc tự động hóa, đem lại sự kết hợp giữa hệ thống ảo và thực tế. Cuộc cách mạng này tác động mạnh mẽ đến nhiều lĩnh vực, nhiều khía cạnh trong đời sống xã hội, trong đó đặc biệt không thể thiếu một nguồn nhân lực chất lượng cao - chính là đối tượng và sản phẩm trực tiếp của giáo dục - đào tạo. Vì vậy, tầm quan trọng của giáo dục - đào tạo trong việc đào tạo nguồn nhân lực đáp ứng yêu cầu cách mạng 4.0 là không thể phủ nhận.

Nhiều trường đại học đa ngành định hướng nghiên cứu trong nước [1], [2], [3] nhận thấy rằng, phương pháp tiếp cận $\mathrm{CDIO}$, một sáng kiến và phương pháp luận cho cải cách giáo dục 
kỹ thuật, với Chuẩn đầu ra $(\mathrm{CRĐ)} \mathrm{của} \mathrm{chương} \mathrm{trình} \mathrm{đào} \mathrm{tạo}(\mathrm{CT}$ T), Đề cương $\mathrm{CDIO}$ và một bộ gồm 12 Tiêu chuẩn đánh giá theo CDIO, giúp giải đáp những câu hỏi "dạy cái gì" và "dạy như thế nào" theo cách thức có hệ thống và không bắt buộc, do đó khả thi để giải quyết những yêu cầu và điều kiện đặc thù của các cơ sở giáo dục (CSGD) khác nhau.

Thuật ngữ CDIO - là viết tắt của cụm từ tiếng Anh Conceive - Design - Implement Operate, có nghĩa là: hình thành ý tưởng, thiết kế ý tưởng, thực hiện ý tưởng và vận hành hệ thống - đây chính là bộ năng lực yêu cầu của một sinh viên ngành kỹ thuật khi tốt nghiệp đại học. Khung giảng dạy và học tập CDIO được khởi nguồn từ Viện Công nghệ MIT (Hoa Kỳ) và mô hình này được phổ biến áp dụng tại các trường Đại học nổi tiếng trên thế giới [4], [5], [6]. Mô hình CDIO được bắt đầu áp dụng tại ĐHQG-HCM vào năm 2010, bằng việc thí điểm cho một số CTÐT. Việc thí điểm được đánh giá định kỳ. Sau 3 năm thí điểm thành công và đúc kết những kết quả, kinh nghiệm ban đầu [3], từ năm 2013, CDIO được mở rộng triển khai cho các CTĐT kỹ thuật, phi kỹ thuật trong các cơ sở giáo dục khác nhau ở Việt Nam.

Trong công văn số 4925/BGDĐT-GDĐH ngày 25 tháng 10 năm 2018 [7], Bộ Giáo dục và Đạo tạo đã có chỉ đạo về việc hợp tác đổi mới chương trình đào tạo theo tiệp cận CDIO gồm năm trường đại học kỹ thuật lớn trong nước gồm: Đại học Xây dựng, Đại học Kiến trúc Hà Nội, Đại học Thủy lợi, Đại học Giao thông vận tải và Đại học Mỏ - Địa chất (hình 1).

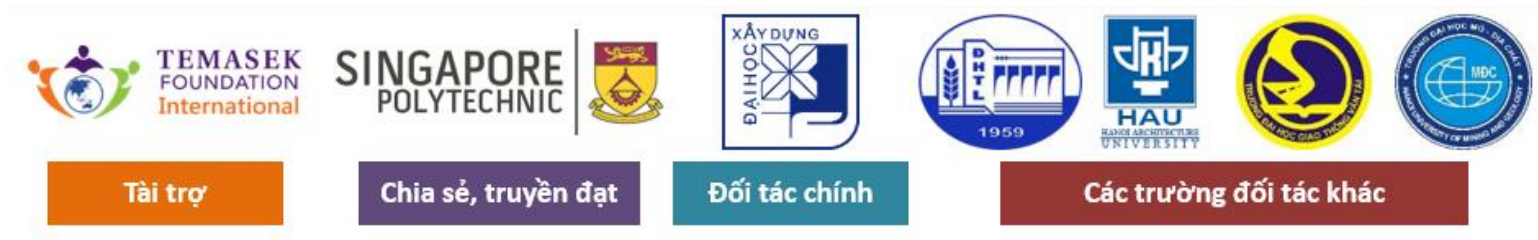

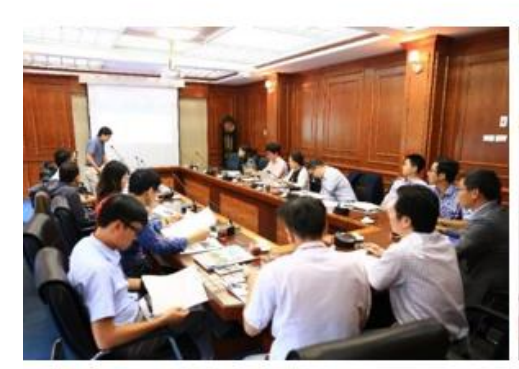

Cuộc họp đầu tiên giữa Trường Singapore Polytechnic và các trường $Đ H$ Việt Nam 11/09/2018

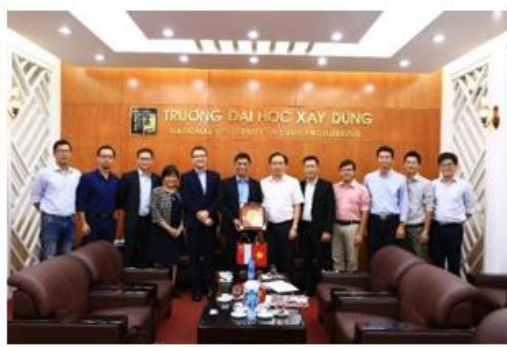

Họp với Quỹ Temasek Quốc tế với sự chứng kiến của đại diện Bộ Giáo dục \& Đào tạo

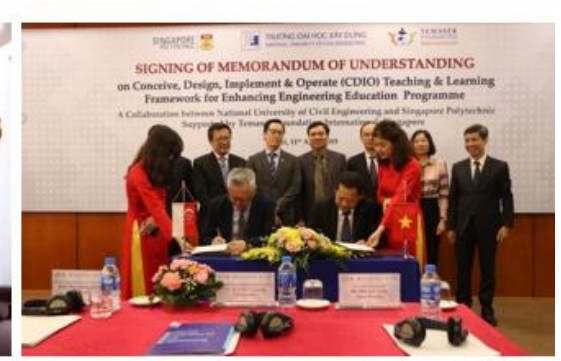

Lễ ký kết Biên bản thỏa thuận về triển khai Dự án $15-16 / 01 / 2019$

Hinh 1. Dự án triển khai Khung giảng dạy, học tập theo CDIO với Quỹ Temasek Quốc tế và Truò̀ng Singapore Polytechnic với các đối tác Việt Nam

Theo nhiều nghiên cứu [8], [9], [10] đã cho thấy rằng, nói chung CDIO không chỉ cung cấp một phương pháp đào tạo mà còn là một khung hướng dẫn rõ ràng về đào tạo, giảng dạy, học tập và quản lý giáo dục như: phương pháp lãnh đạo, quản lý giáo dục đại học, phát triển đội ngũ giảng viên với chuyên môn sâu, gắn chặt doanh nghiệp với cơ sở giáo dục, phương pháp học tập dựa trên dự án, nhóm, cải cách chương trình khung, cung cấp kỹ năng giao tiếp, học tập dựa trên kinh nghiệm và chủ động, thiết kế chương trình đào tạo, môi trường học tập, cách kiểm tra và đánh giá, quốc tế hóa giáo dục đại học... Do vậy, 
có thể nói, đào tạo đáp ứng nhu cầu của xã hội và hội nhập quốc tế: Mô hình CDIO - là một trong những giải pháp rất hữu ích để nâng cao chất lượng chương trình đào tạo và giáo dục đại học hiện nay (hình 2).

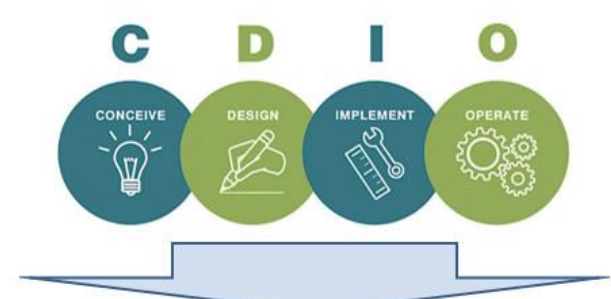

Đảm bảo cho người học có được kiến thức, kỹ năng và thái độ phù hợp với yêu cầu của nhà tuyển dụng trong bối cảnh hội nhập quốc tế hiện nay.

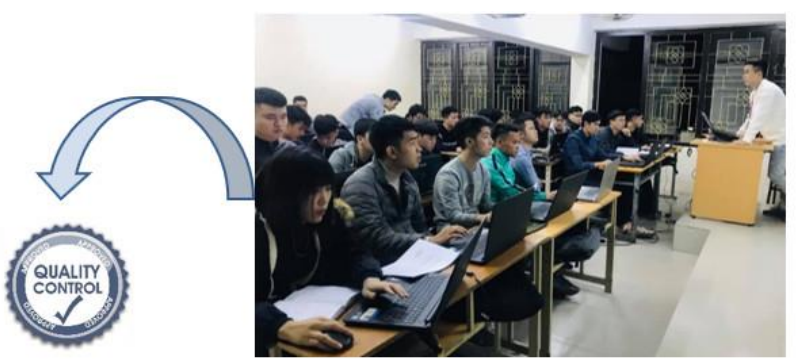

Tạo điều kiện để chương trình đào tạo hướng đến các chuẩn kiểm định chất lượng, uy tín như AUN-QA, ABET (đối với kỹ thuật và công nghệ), NAAB (đối với kiến trúc).

Hình 2. Mục tiêu khung đào tạo và giảng dạy theo CDIO

Bộ tiêu chuẩn đánh giá chất lượng CSGD hiện hành, ban hành theo Thông tư 12/2017/TT-BGDĐT, được xây dựng dựa trên cơ sở bộ tiêu chuẩn đánh giá cơ sở giáo dục do Mạng lưới các trường đại học ASEAN (AUN-QA) ban hành tháng 7/2016 (Guide to AUN-QA Assessment At Institutional Level (ver 2.0)). Theo đó, bộ tiêu chuẩn này gồm có 25 tiêu chuẩn, 111 tiêu chí, đánh giá toàn bộ hoạt động của một cơ sở giáo dục đại học, được chia thành 4 nhóm:

- Đảm bảo chất lượng về mặt chiến lược (08 tiêu chuẩn, 37 tiêu chí;

- Đảm bảo chất lượng về mặt hệ thống (04 tiêu chuẩn, 19 tiêu chí);

- Đảm bảo chất lượng về mặt thực hiện chức năng (09 tiêu chuẩn, 39 tiêu chí);

- Kết quả hoạt động (04 tiêu chuẩn, 16 tiêu chí).

Trong thời gian tới là giai đoạn đất nước triển khai Chiến lược phát triển kinh tế - xã hội giai đoạn 2021 - 2030 tầm nhìn 2045, đưa Việt Nam cơ bản trở thành một nước công nghiệp theo hướng hiện đại, đồng thời tiếp tục hội nhập quốc tế sâu rộng trên tất cả các lĩnh vực của đời sống xã hội, theo đó nhiều trường đại học nước ngoài sẽ đầu tư vào Việt Nam; nhiều tổ chức, công ty, doanh nghiệp sẽ đầu tư vào lĩnh vực giáo dục Việt Nam; song song với đó là việc áp dụng cơ chế tự chủ đối với các cơ sở giáo dục đại học theo Luật giáo dục đại học và Nghị định 99. Do đó, nhu cầu về nguồn nhân lực chất lượng cao sẽ ngày càng lớn, tạo ra sự cạnh tranh mạnh mẽ trong đào tạo nguồn nhân lực cho xã hội. Năm năm tới sẽ có sự thay đổi cơ bản, toàn diện về giáo dục theo chiến lược phát triển ngành giáo dục Việt Nam, có sự thay đổi về định hướng phát triển khoa học công nghệ của cả nước.

Bên cạnh đó, một trong những thách thức chính yếu mà các trường đại học $(\mathrm{DH})$ trong nước phải đối mặt là làm thế nào để đào tạo được người học đáp ứng nhu cầu phát triển của xã hội. Vì thế, việc áp dụng phương pháp CDIO trong xây dựng chương trình đào tạo và tổ chức đào tạo là rất cần thiết. Theo [2], [11] có ba thành tố quan trọng trong CDIO được thực hiện chặt chẽ theo quy trình và điều chỉnh liên tục theo thời gian đảm bảo yếu tố 
phù hợp theo bối cảnh là: (i) - các chuẩn đầu ra dự định (Intended learning outcomes); (ii) - các hoạt động dạy và học (Teaching and learning activities); (iii) - đánh giá (Assessment).

Với sự đa dạng hóa quá trình đào tạo, trong nhiều nghiên cứu hiện nay đã thừa nhận nguyên lý rằng việc phát triển và triển khai vòng đời của công trình, sản phẩm, quy trình hoặc hệ thống theo CDIO - là bối cảnh của giáo dục, đào tạo kỹ thuật trong cuộc cách mạng công nghiệp 4.0 [12], [13]. Đặc điểm nổi bật của phương pháp đào tạo theo CDIO là chương học tập tích hợp và trải nghiệm chủ động. Khung giảng dạy và học tập theo CDIO nhằm trả lời hai câu hỏi lớn về giảng dạy và học tập.

Thứ nhất: Dạy cái gì?

Theo [4], khung giảng dạy nhằm mục tiêu đạt được CĐR CDIO, bao gồm:

- Kiến thức và lập luận ngành;

- Phẩm chất, kỹ năng cá nhân và nghề nghiệp;

• Kỹ năng làm việc nhóm và giao tiếp;

• Kỹ năng CDIO (Hình thành ý tưởng, thiết kế, thực hiện, vận hành).

\section{Thứ hai: Dạy như thế nào?}

Mô hình giảng dạy và học tập theo CDIO gồm có 12 tiêu chuẩn (TC) (hình 1), dựa trên các cơ sở như sau:

- CTĐT tích hợp;

- Phương pháp dạy và học;

- Đánh giá sinh viên;

- Tăng cường năng lực giảng viên;

- Không gian học tập và không gian kỹ thuật CDIO.

\section{Quá trình rà soát, điều chỉnh và xây dựng CTĐT theo tiếp cận CDIO và chuẩn quốc tế trên cơ sở điều kiện vật chất hiện có của các CSGD đại học trong nước}

\section{1. Đối với Trường Đại học Xây dụng}

Theo nhiều nghiên cứu hiện nay đã cho thấy, mục tiêu giáo dục trong giai đoạn cách mạng công nghiệp 4.0 là: sáng tạo và tạo ra giá trị với chương trình đạo tạo xuyên ngành, học mọi nơi, internet kết nối vạn vật, đảm bảo chất lượng theo nguyên tắc, trường học và hệ sinh thái, sinh viên tốt nghiệp là người sáng tạo và khởi nghiệp. Sinh viên hình thành ý tưởng và đề xuất phương án kết cấu dựa trên đề bài là một công trình trên thực tế, sau đó sinh viên phải thuyết trình và bảo vệ được phương án kết cấu mà nhóm mình đã lựa chọn (GV đóng vai chủ đầu tư để đặt câu hỏi). Hoạt động học tập này giúp sinh viên áp dụng kiến thức đã được dạy về hành văn và thuyết trình trong lĩnh vực kỹ thuật. Quá trình xây dựng, đổi mới, cái tiến CTĐT tại Trường ĐHXD được thể hiện trên hình 3 và 4 . 

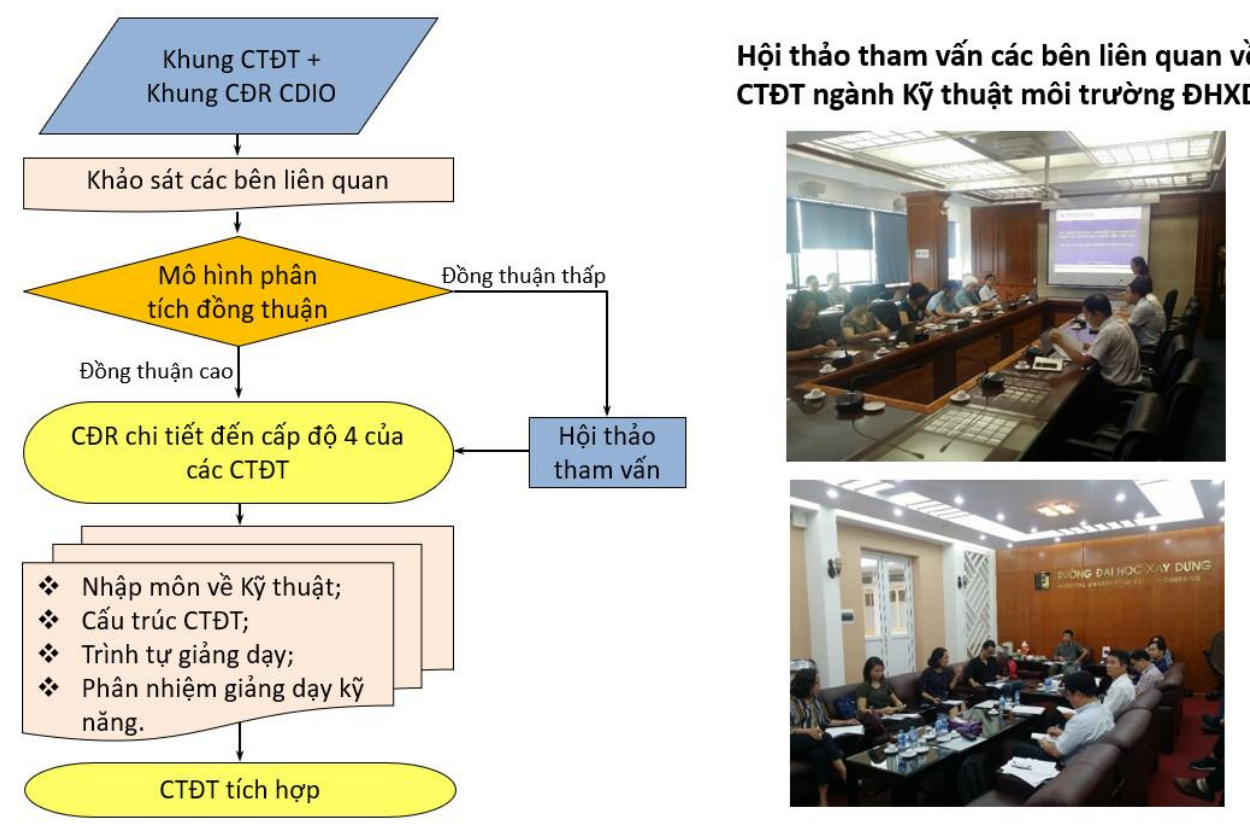

Hình 3. Mô hình triển khai đổi mới CTĐT tại Trường ĐHXD
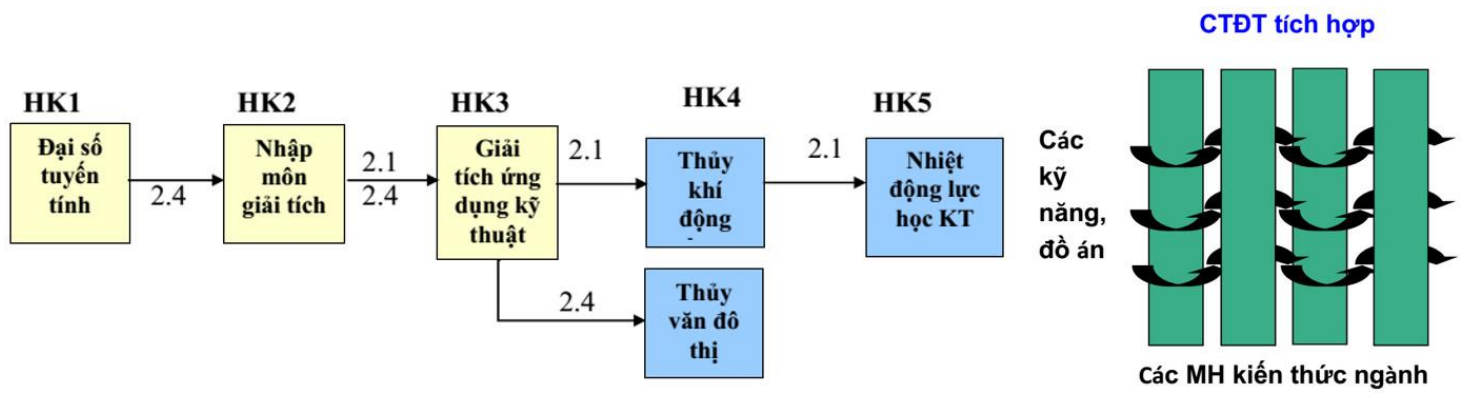

Hình 4. Cải cách CTĐT tại Trường ĐHXD

\section{2. Đối với các CTĐT tại Truò̀ng ĐH Bách Khoa HCM}

“Từ một CTĐT Kỹ thuật Cơ khí của Trường ĐH Bách Khoa HCM, tiên phong áp dụng CDIO từ năm 2010, đến năm 2014, tất cả 33 ngành đào tạo của Trường ĐH Bách Khoa được đổi mới dựa trên mô hình $\mathrm{CDIO}$ - chú trọng giảng dạy tích hợp các kiến thức, kỹ năng và thái độ, đáp ứng kỳ vọng của các bên liên quan. Các CTĐT của trường đã nhận được nhiều đánh giá tích cực từ các tổ chức kiểm định uy tín trong khu vực và thế giới” [14].

\section{3. Đối với các CTÐT Báo chí và Truyền thông tại Trưòng ĐH Khoa học Xã hội và Nhân văn (KHXH\&NV)}

"Sinh viên (SV) ngành báo chí và truyền thông có trình độ đầu vào tốt, nên kỳ vọng đối với CTĐT mới là rất cao. Tuy nhiên, $\mathrm{CTĐT} \mathrm{trước} \mathrm{đây,} \mathrm{được} \mathrm{thiết} \mathrm{kế} \mathrm{chủ} \mathrm{yếu} \mathrm{dựa} \mathrm{vào}$ kinh nghiệm, thiếu một khung lý luận, chuẩn đầu ra của từng học phần và một quy trình để nhận diện nhu cầu xã hội, đồng thời thiếu các thiết kế mục tiêu, xây dựng chuẩn đầu ra và truyền tải các yêu cầu chuẩn đầu ra vào chương trình.

Mặc dù khoa đã có những nỗ lực cải tiến liên tục, trong đó module hóa CTDH theo cách tích hợp vào các học đại cương, cơ sở ngành và chuyên ngành, nhưng cũng chỉ dừng ở mức độ lắp ghép mà chưa có một hệ thống mô tả và phân tích cụ thể và vững chắc. $\mathrm{CDIO}$ giúp khoa có 
được một cách tiếp cận đáp ứng các yêu cầu này và một lộ trình để tái thiết kế CTĐT và giảng dạy nhằm đáp ứng cao hơn và bền vững hơn nhu cầu thực tiễn của nghề nghiệp" [15].

\section{4. Đối với Truờng Đại học Quốc gia HCM (ĐHQG-HCM)}

CTĐT Kỹ thuật Cơ khí tại Trường ĐH Bách Khoa $(\mathrm{BK})$ và các CTĐT máy tính và công nghệ thông tin (CNTT) tại Trường ĐH Khoa học Tự nhiên (KHTN) đã được chọn để tham gia áp dụng CDIO một cách hệ thống, nhằm 02 mục tiêu chính như sau [16]:

- Cung cấp cho sinh viên các kiến thức, kỹ năng, phẩm chất, và năng lực nghề nghiệp toàn diện, đáp ứng nhu cầu của các bên liên quan.

- Sử dụng việc thí điểm để đúc kết những sản phẩm và mô hình mẫu, khung chuẩn chung phát triển CTĐT để nhân rộng triển khai tại ĐHQG-HCM và các cơ sở GDĐH Việt Nam.

Có thể tóm lược mô hình triển khai và áp dụng CDIO của ĐHQG-HCM như thể hiện bởi Hình 5. Việc đúc kết ở giai đoạn đầu được thực hiện chủ yếu với 5 CTĐT thí điểm, ở giai đoạn nhân rộng triển khai, được tiến hành với cả các CTĐT ở các lĩnh vực khác nhau.

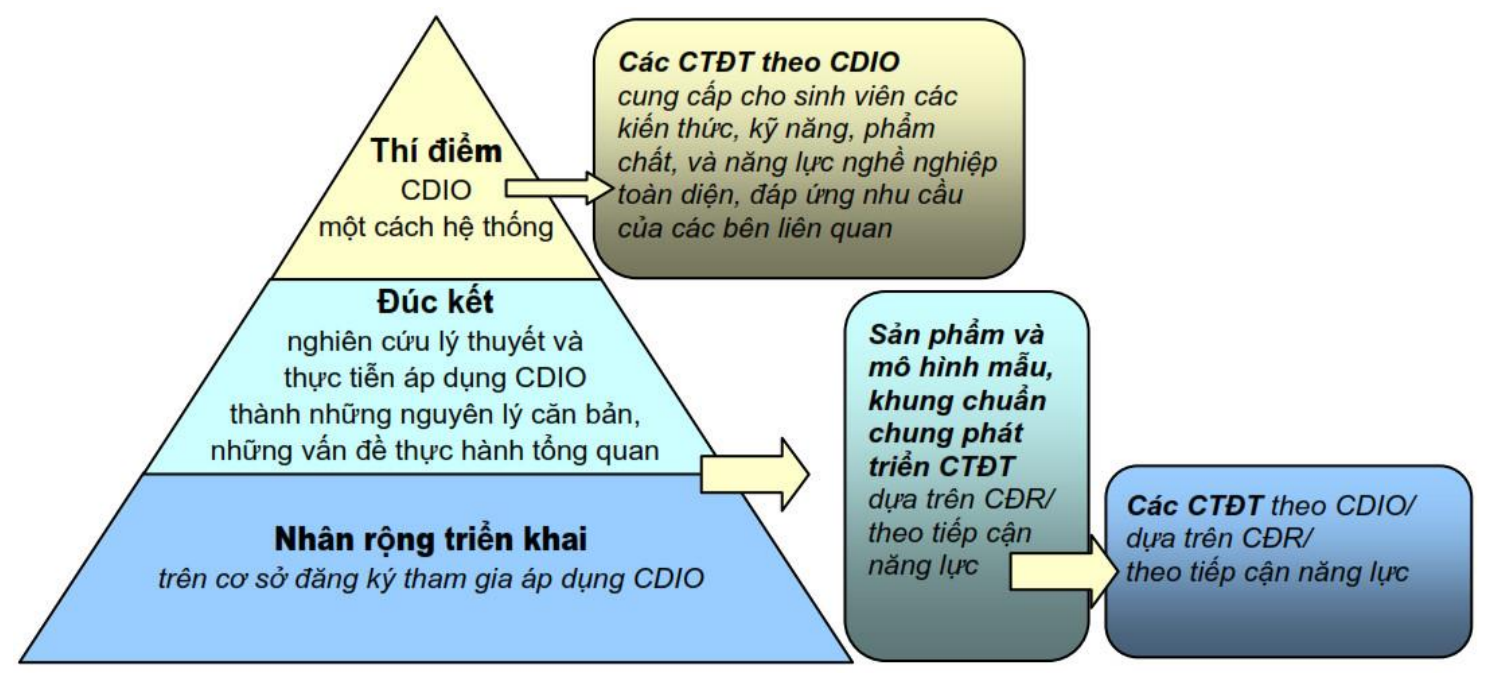

Hình 5. Mô hình triển khai và áp dụng khung CDIO của ĐHQG-HCM đến năm 2016

\section{5. Đối với Trường Đại học Giao Thông Vận Tải}

Nhà trường đã xây dựng được quy trình hướng dẫn xây dựng chương trình đào tạo, phương pháp giảng dạy, kiểm tra - đánh giá theo CDIO [2]. Tương ứng với các tiêu chuẩn CDIO, CTĐT đã được đổi mới như sau:

- Triết lý, mục tiêu và bối cảnh đào tạo được xác định rõ ràng;

- CĐR được xây dựng toàn diện, cụ thể, đáp ứng nhu cầu của các bên liên quan;

- CTGD được thiết kế tích hợp giảng dạy kỹ năng với kiến thức và phát triển phẩm chất CSVC, TTB thực hành được sắp xếp hợp lý hóa/đầu tư;

- Đội ngũ GV được tăng cường kỹ năng CDIO/kỹ năng nghề nghiệp, kỹ năng sư phạm;

- CTGD được thực hiện nhất quán với $\mathrm{CĐR}$ của từng học phần nhằm mục đích đạt được chuẩn đầu ra chung của ngành đào tạo;

- CTĐT được kiểm tra, ra soát và đánh giá định kỳ; 


\section{6. Đối với Truò̀ng Đại học Mỏ - Địa chất}

Nhận thức được rõ tầm quan trọng trong đào tạo nguồn nhân lực trong giai đoạn cách mạng công nghiệp 4.0, đồng thời đảm bảo cho người học có được kiến thức, kỹ năng và thái độ phù hợp với yêu cầu của nhà tuyển dụng trong bối cảnh hội nhập quốc tế hiện nay, Trường đại học Mỏ - Địa chất đã xác định rõ triết lý giáo dục của Nhà trường [17], bao gồm:

Nhân văn: Trường Đại học Mỏ - Địa chất đào tạo người học vừa có kiến thức chuyên sâu, có khát vọng vươn lên, có phẩm giá, tình cảm, văn hóa tốt;

Khai phóng: Trường Đại học Mỏ - Địa chất cung cấp, trang bị cho người học những kiến thức và kỹ năng toàn diện, năng lực thích ứng linh hoạt trong bất cứ môi trường làm việc nào, có đạo đức tốt, phát triển phong cách và lối sống có trách nhiệm với xã hội;

Hội nhập: Tăng cường kết nối giữa Nhà Trường với các cá nhân, tổ chức có liên quan, tiếp thu các chuẩn mực, giá trị văn hóa, sản phẩm khoa học tiến bộ của thế giới để nâng cao chất lượng đào tạo và nghiên cứu khoa học của Trường.

Với những cố gắng rà soát, chỉnh sửa $\mathrm{CTĐT} \mathrm{và} \mathrm{nâng} \mathrm{cao} \mathrm{chất} \mathrm{lượng} \mathrm{đào} \mathrm{tạo} \mathrm{và}$ nghiên cứu khoa học, trong năm 2019, Nhà trường đã được đánh giá ngoài và kiểm định chất lượng bởi Trung tâm Kiểm định chất lượng giáo dục, Đại học Quốc gia Hà Nội (VNUCEA) với tỷ lệ tiêu chí đạt yêu cầu là $85.2 \%$. Giấy chứng nhận số 33/GCN-CSGD được cấp ngày 30/3/2018. Đến tháng 5/2020, Trường Đại học Mỏ - Địa chất tham gia xếp hạng các trường đại học theo hệ thống UPM và đạt chuẩn 4 sao theo định hướng đại học nghiên cứu, được cấp Chứng nhận vào ngày 18/8/2020 [18].

\section{Hiệu quả áp dụng tiếp cận CDIO trong trường đại học - số liệu cụ thể tại trường ĐHMĐC}

\subsection{Chuẩn đầu ra của CTÐT}

Chuẩn đầu ra $(\mathrm{CĐR})$ của $\mathrm{CTĐT} \mathrm{bao} \mathrm{gồm} \mathrm{những} \mathrm{chuẩn} \mathrm{đầu} \mathrm{ra} \mathrm{chi} \mathrm{tiết,} \mathrm{cụ} \mathrm{thể} \mathrm{đối} \mathrm{với}$ kỹ năng cá nhân và giao tiếp, kỹ năng kiến tạo sản phẩm, quy trình, và hệ thống, cũng như các kiến thức chuyên môn, phải nhất quán với các mục tiêu của chương trình, và được phê chuẩn bởi các bên liên quan của CTĐT.

CĐR của CTĐT của ĐHMĐC đã được công bố lần đầu vào năm 2013 và sau đó được điều chỉnh vào các năm 2016, 2018 và 2020. CĐR của CTĐT (ban hành năm 2016 và năm 2018) được mô tả tương đối rõ ràng, súc tích, dễ hiểu. CĐR của CTĐT đáp ứng Khung trình độ Quốc gia Việt Nam, đồng thời thể hiện được yêu cầu riêng của từng ngành đạo tạo trong Trường Đại học Mỏ - Địa chất. Các chuẩn chung về kiến thức, kỹ năng, mức tự chủ và trách nhiệm đã được cụ thể hoá trong lĩnh vực Kỹ thuật xây dựng.

Nhà trường đã ban hành Quy định về xây dựng, điều chỉnh CĐR và CTĐT tại quyết định số 3598/QĐ-MĐC ngày 17/12/2015; định kỳ thực hiện rà soát điều chỉnh CĐR của CTĐT vào năm 2016 và 2018. Kết quả khảo sát cho thấy có tới $95.7 \%$ nhà tuyển dụng hài lòng và rất hài lòng với kiến thức và kỹ năng của $\mathrm{SV}$. Cũng có đến $93 \%$ người học được hỏi ý kiến đồng ý và hoàn toàn về sự phù hợp giữa $\mathrm{CTĐT}$ và $\mathrm{CĐR}$, cùng với $88 \% \mathrm{SV}$ cho thấy tỷ lệ giữa lý thuyết và thực hành là hợp lý. 


\section{2. Đổi mới, nâng cao và tích hợp CTÐT}

Thiết kế chương trình đào tạo của Nhà trường đã từng bước tích hợp theo tiếp cận CDIO và được góp ý của các biên liên quan, nhằm mục đích nhận dạng các kỹ năng, dạy kỹ năng, phát triển kỹ năng và đánh giá kỹ năng. Chương trình đào tạo của ĐHMĐC đã được rà soát, điều chỉnh vào những năm 2016, 2018 và 2020 . Hiện nay ĐHMĐC đang và đã xây dựng CTĐT thích hợp theo tiếp cận mô hình $\mathrm{CDIO}$, đó là chương trình được thiết kế có các khóa học kiến thức chuyên ngành hỗ trợ lẫn nhau, có một kế hoạch rõ ràng trong việc tích hợp các kỹ năng cá nhân, giao tiếp, kiến tạo sản phẩm, lập quy trình quy trình và hệ thống.

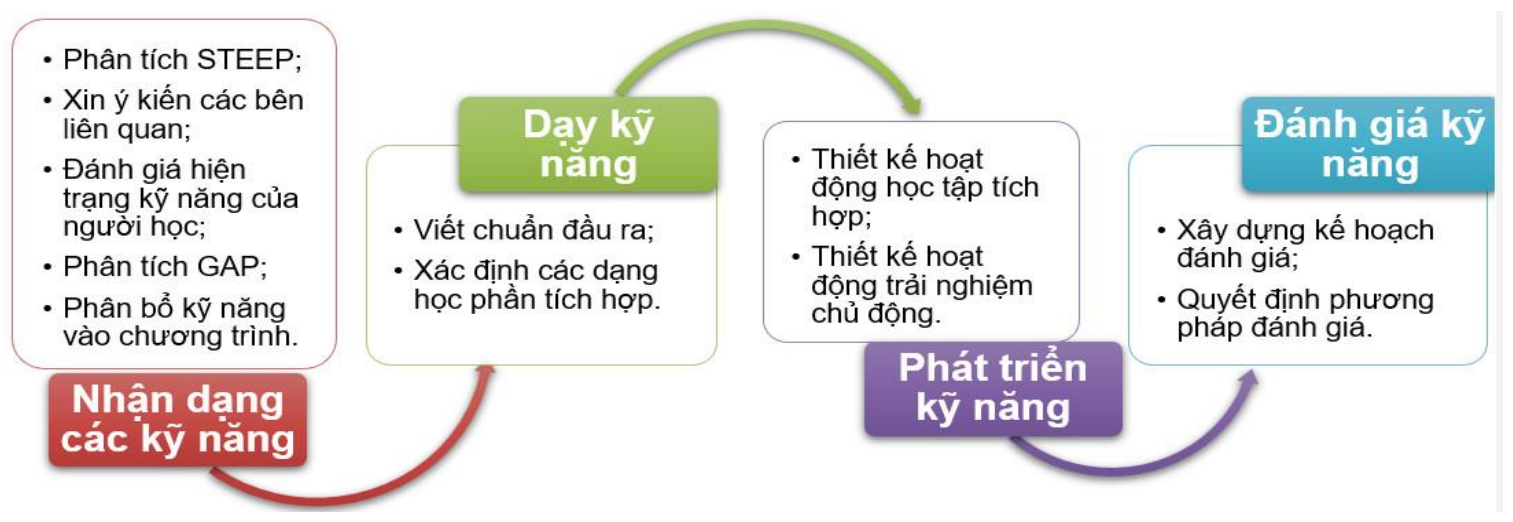

Hinh 6. Thiết kế chương trình đào tạo tích hơp

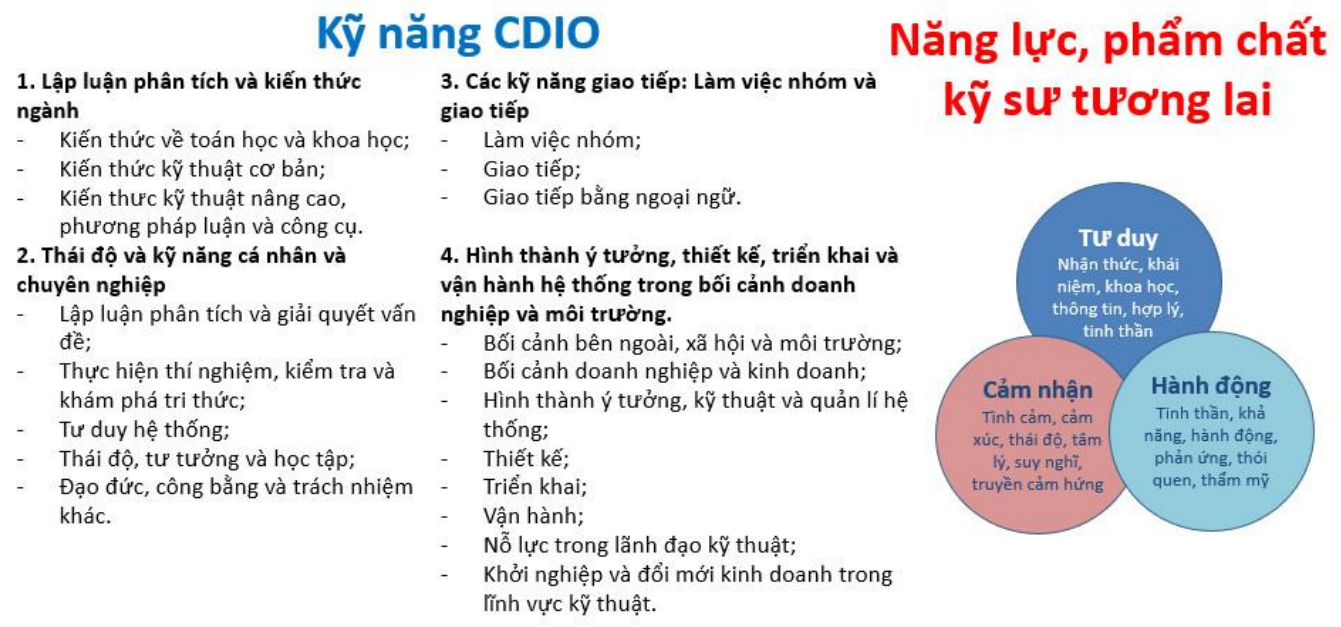

Hình 7. Khung kỹ năng theo CDIO

Trong nhiều nghiên cứu [4], [19] đã chỉ rõ, CTĐT tích hợp thông qua 5 bước, nhằm mục đích nâng cao khả năng tự học, tự chiếm hữu kiến thức của người học (Hình 6).

Chương trình đào tạo tích hợp bao gồm các trải nghiệm học tập nhằm giúp sinh viên lĩnh hội được các kỹ năng cá nhân, giao tiếp, kiến tạo sản phẩm, lập quy trình, hệ thống hóa bên cạnh với việc học kiến thức chuyên ngành, những kỹ năng này đã được quy định trong khung học tập và giảng dạy CDIO (hình 7). Các môn học chuyên ngành hỗ trợ lẫn nhau khi chúng có mối liên hệ rõ ràng giữa các nội dung hỗ trợ và các chuẩn đầu ra liên quan, từ đó hình thành năng lực và phẩm chất của người kỹ sư trong tương lai. 


\subsection{Phuơng pháp tiếp cận trong giảng dạy và học tập}

Mục tiêu giáo dục cũng như triết lý giáo dục của Trường đã được phổ biến rộng rãi đến các bên liên quan qua các hình thức: Quán triệt, phổ biến đến tất cả cán bộ $\mathrm{GV}, \mathrm{SV}$ của các đơn vị trong trường để hiểu rõ và thực hiện (kết quả phỏng vấn); công bố công khai trên trang thông tin điện tử của Trường, in trong Sổ tay sinh viên và trong các ấn phẩm quảng bá về Trường.

Hằng năm, Nhà trường đều khảo sát sự hài lòng của người học về chất lượng hoạt động dạy và học. Kết quả khảo sát năm học 2018-2019 có 95,6\% ý kiến hài lòng về hoạt động giảng dạy của GV. Ý kiến của người học trong buổi phỏng vấn đều đánh giá cao phương pháp giảng dạy của GV.

Nhà trường/Khoa đã xây dựng các tổ hợp dạy học thích hợp, đặc biệt là những tổ hợp nâng cao được kỹ năng, phương pháp tự học của người học. Việc giảng dạy được kết hợp với tổ chức cho $\mathrm{SV}$ thảo luận, làm bài tập và làm đồ án môn học. Bên cạnh đó ĐHMĐC đã tổ chức Diễn đàn "Hành trình người khởi nghiệp" cho học sinh, sinh viên, đối thoại giữa sinh viên với lãnh đạo nhà truờng hàng năm, nhằm muc đích giáo dục và lan tỏa lòng yêu nghề và ý thức vượt khó, say mê với ngành nghề đã chọn của $\mathrm{NH}$.

\section{4. Đánh giá kết quả học tập của nguoòi học}

Nhà trường đã ban hành Quy trình khảo thí kết thúc học phần đối với sinh viên đại học, cao đẳng (Quyết định số 2070/QĐ-MĐC ngày 18/11/2016). Các quy định và kế hoạch đánh giá kết quả học tập của $\mathrm{SV}$ được gửi theo đường văn thư đến các đơn vị, được công bố công khai trên cổng thông tin đào tạo của Trường, được in trong "Sổ tay sinh viên", được phổ biến cho SV trong "Tuần sinh hoạt công dân" đầu mỗi năm học. Kế hoạch và nội dung KTĐG của mỗi học phần đều được $\mathrm{GV}$ phổ biến và cung cấp đề cương học phần cho $\mathrm{SV}$ vào buổi học đầu tiên.

Phương pháp KTĐG của CTĐT được các đơn vị và GV thực hiện tương đối đa dạng, phù hợp với các quy định của Nhà trường. Việc tổ chức thi kết thúc học phần được thực hiện nghiêm túc, đúng quy chế. Quy trình ra đề thi đảm bảo độ bảo mật cao.

Kết quả học tập được công bố kịp thời đến $\mathrm{SV}$ đã giúp họ chủ động trong việc lập kế hoạch học tập cho kỳ tiếp theo cũng như đổi mới phương pháp học tập để có kết quả tốt hơn. Ngoài ra, Phòng ĐT còn thực hiện tốt việc cảnh báo học tập đối với những SV có kết quả yếu. Các quy định về phúc khảo kết quả thi được công bố công khai trên trang thông tin điện tử của Trường và trong cuốn Sổ tay sinh viên. Đa số $\mathrm{SV}$ đều nắm được quy định về việc phúc khảo bài thi.

\section{5. Đội ngũ $G V$, nghiên cứu viên}

Nhà trường có Chiến lược phát triển Trường ĐHMĐC giai đoạn 2008-2020, tầm nhìn 2030; Quy hoạch và kế hoạch phát triển đội ngũ; Kế hoạch phát triển đội ngũ giai đoạn 20152020; Đề án vị trí việc làm của đội ngũ cán bộ $\mathrm{CB}$ ), giáo viên $(\mathrm{GV})$, nhân viên $(\mathrm{NV})$. Ban hành đầy đủ các Quy chế, quy định tuyển dụng, sử dụng và quản lý $\mathrm{CB}, \mathrm{GV}, \mathrm{NV}$; kết quả thực hiện được công bố công khai trong toàn Trường. Kế hoạch ĐTBD đội ngũ $\mathrm{CB}, \mathrm{GV}, \mathrm{NV}$ được xây dựng trên nhu cầu $\mathrm{T}, \mathrm{NCKH}$; nhu cầu của $\mathrm{CB}, \mathrm{GV}, \mathrm{NV}$ của các đơn vị/Khoa. 


\subsection{Nâng cao chất lượng}

ĐHMĐC đã có hệ thống thu thập thông tin phản hồi từ các bên liên quan giúp cho việc thiết kế phát triển $\mathrm{CTDH}$ (CTĐT), có phân công trách nhiệm các đơn vị và các văn bản quy định hướng dẫn đầy đủ. Các mẫu phiếu khảo sát được sử dụng năm 2017 và 2019 có nhiều nội dung khảo sát phục vụ phát triển CTDH. Thông tin phản hồi đã được sử dụng trong việc cải tiến chất lượng CTDH các năm 2017 và 2019.

Hệ thống văn bản hướng dẫn quy trình xây dựng và phát triển CTDH/CTĐT đã được ban hành tương đối đầy đủ, có rà soát và cải tiến, được triển khai thực hiện từ cấp bộ môn.

Các văn bản về tổ chức và quản lý đào tạo của ĐHMĐC có các nội dung quy định về việc rà soát đánh giá quá trình dạy học và kiểm tra đánh giá kết quả học tập của người học, quy định trách nhiệm của các đơn vị chức năng và GV, SV trong hoạt động dạy - học. Nhiều hoạt động rà soát đánh giá quá trình dạy học như dự giờ, thao giảng, hội nghị đào tạo, sinh hoạt bộ môn, giám sát và thanh tra dạy học,..., rà soát và cải tiến công tác khảo thí. Tỷ lệ hài lòng của $S V$ về giảng dạy và khảo thí khá cao.

Chất lượng các dịch vụ hỗ trợ như thư viện, phòng thí nghiệm, hệ thống CNTT, công tác tư vấn học tập, hoạt động ngoài giờ, văn nghệ thể thao,... được ĐHMĐC và khoa chuyên môn quan tâm, liên tục đầu tư, cải tiến chất lượng phục vụ. Kết quả khảo sát ý kiến của $S V$ và $G V$ vào năm 2017 và 2019 đánh giá chất lượng các dịch vụ hỗ trợ phục vụ dạy học với mức hài lòng khá cao (trên 4,0/5).

Cơ chế phản hồi của các bên liên quan đối với CTĐT KTXD đa dạng và có hệ thống với sự tham gia của nhiều đơn vị, bộ phận chức năng trong trường và khoa, được phân công và hướng dẫn bằng các văn bản qui định, từng bước được rà soát và cải tiến vào các năm 2016, 2018 và 2019.

\subsection{Kết quả đầu ra}

Từ kết quả khảo sát đánh giá ngoài năm 2020 [20], cho thấy tỉ lệ thôi học, tốt nghiệp đúng hạn (không kể thời gian kéo dài) được xác lập. Danh sách thôi học, tốt nghiệp được cập nhật, được đánh giá, phân tích, giám sát, được đối sánh hằng năm để cải tiến chất lượng CTÐТ. ĐHMĐC có bộ phận, quy trình thống kê và lưu trữ danh sách $\mathrm{NH}$ tốt nghiệp có việc làm, vị trí làm việc, mức thu nhập bình quân, đơn vị công tác trong thời gian đánh giá; có số liệu tin cậy về tỉ lệ NH có việc làm trong vòng 12 tháng sau khi tốt nghiệp; đã thực hiện đối sánh tỉ lệ $\mathrm{NH}$ tốt nghiệp có việc làm giữa các $\mathrm{CT} \mathrm{TT}$ trong Trường và tổ chức thảo luận, phân tích nguyên nhân, đề xuất các biện pháp khắc phục; thực hiện các phương án hỗ trợ NH tốt nghiệp có việc làm. Tỷ lệ có việc làm hoặc tiếp tục đi học của $S V$ ngành KTXD của ĐHMĐC sau khi tốt nghiệp/số SV phản hồi khảo sát là khá cao trong cả 2 năm khảo sát 2017 và 2018 lần lượt là 97.5 và $96.7 \%$. Tuy nhiên, tỷ lệ $\mathrm{SV}$ có việc làm không liên quan đến ngành được đào tạo cũng tương đối cao $(31 / 156=20 \%$ và $63 / 290=22 \%$ lần lượt với các khảo sát SV tốt nghiệp năm 2017 và 2018). Tỷ lệ này thấp hơn hẳn so với 5 trong số 7 CTĐT được ĐGN trong tháng 9 năm 2020 và chỉ cao hơn CTĐT ngành CNTT (số liệu khảo sát 2017 và 2018). Ngoài ra, tỷ lệ SVTN có ý kiến phản hồi trong 2 đợt khảo sát cũng cao nhất trong số 7 CTĐT [20]. Đã thực hiện thống kê, phân tích, đánh giá mức độ hài lòng của các bên liên quan (cán bộ nhân viên, $\mathrm{GV}, \mathrm{NH}, \mathrm{NH}$ đã tốt nghiệp, nhà tuyển dụng) về hoạt động $\mathrm{NCKH}$, dịch vụ hỗ trợ $\mathrm{GV}, \mathrm{NH}$, cơ sở vật chất... Mức độ hài lòng được so sánh 
với kết quả khảo sát mức độ hài lòng chung toàn trường hoặc của các CTĐT khác trong Trường.

Kết quả khảo sát mức độ hài lòng và đối sánh được sử dụng làm căn cứ lập kế hoạch cải tiến chất lượng. Kết quả đối sánh cho thấy SVTN ngành KTXD được NSDLĐ đánh giá rất cao (>4.02 theo thang Likert 5 bậc) và cao hơn mức trung bình của toàn trường về kiến thức, kỹ năng, phẩm chất thái độ, năng lực thực hiện nhiệm vụ ở tất cả các tiêu chí [20]. Đó phần nào là bức tranh những thuộc tính của người học sau khi tốt nghiệp, được trình bày trên hình 8 .

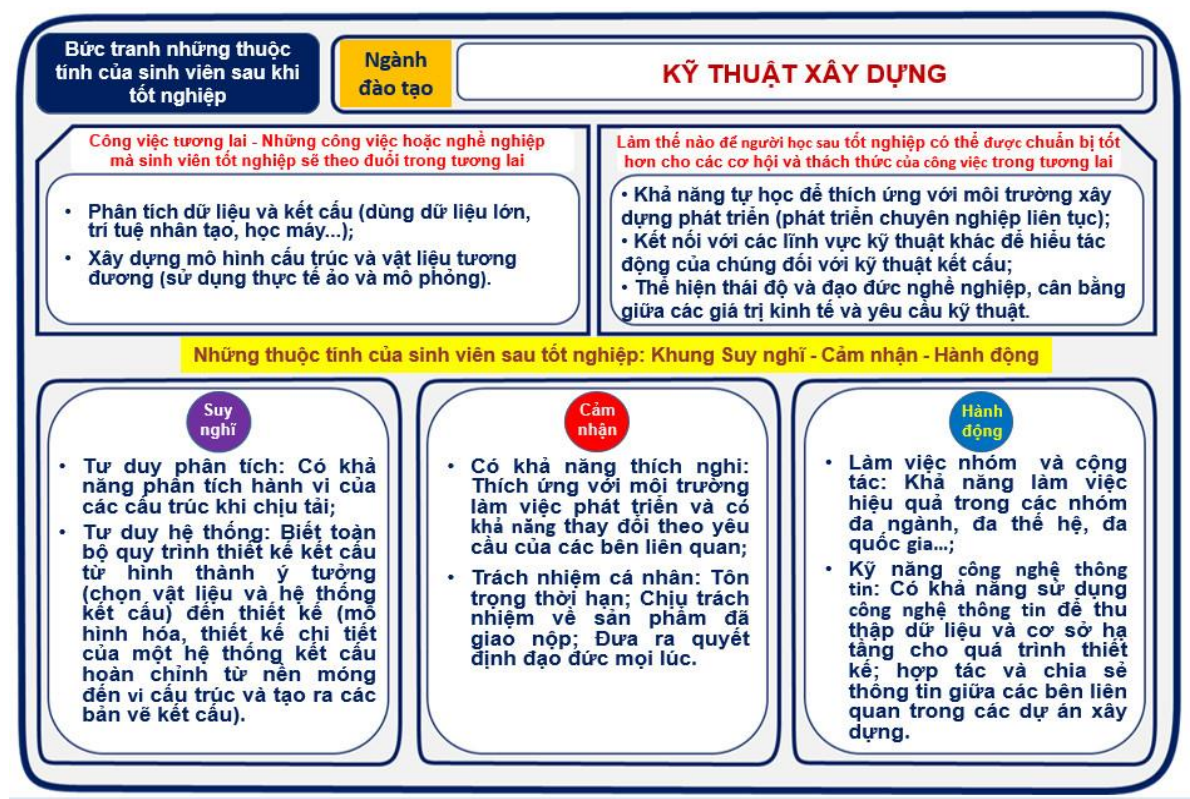

Hình 8. Nhũng thuộc tính của sinh viên sau khi tốt nghiệp của ngành Kỹ thuật xây dựng

Có thể nói, lựa chọn bộ kỹ năng theo mô hình CDIO để đáp ứng năng lực, phẩm chất cần có của người kỹ sư tương lai. Nhiều trường đại học định hướng nghiên cứu hàng đầu ở Việt Nam, trong đó có Đại học Xây dựng, Đại học Giao thông và Đại học Thủy lợi... đã xây dựng CTĐT theo bộ kỹ năng dưới đây để nâng cao năng lực, phẩm chất của người học sau khi tốt nghiệp, nhằm đáp ứng được kiến thức, kỹ năng và thái độ phù hợp với yêu cầu của nhà tuyển dụng trong bối cảnh hội nhập quốc tế hiện nay.

\section{Kết luận}

Dựa trên các phân tích và kết quả khảo sát việc áp dụng CTDH theo tiếp cận CDIO của Trường Đại học Mỏ - Địa chất và một số trường Đại học có thể rút ra một số kết luận sau:

- Thường xuyên kiểm tra đánh giá chất lượng hoạt động đào tạo; xây dựng kế hoạch lộ trình triển khai đồng bộ các hoạt động cải tiến chương trình đảm bảo chất lượng nhằm nâng cao chất lượng chương trình đánh giá ngoài hoạt động đào tạo;

- Cần đổi mới và mở rộng việc đối sánh bằng cách phân tích đầy đủ nguyên nhân của sự khác biệt để từ đó lựa chọn các thực hành tốt nhất, đề xuất các sáng kiến để cải tiến chất lượng CTĐT, ngăn chặn mức giảm tỷ lệ tốt nghiệp. 
- Khi tiến hành đối sánh tỷ lệ $\mathrm{SV}$ có việc làm và việc làm đúng ngành nghề đào tạo với các ngành đào tạo tương đương trong trường cần tìm hiểu, phân tích được nguyên nhân và từ đó đề xuất được những giải pháp để giảm tỷ lệ có việc làm không liên quan đến ngành đào tạo.

- Cần một mặt GD lòng yêu nghề và ý thức vượt khó, say mê với ngành nghề đã chọn. Mặt khác, cần nâng cấp các câu hỏi khảo sát (cụ thể các việc làm khác là gì - lĩnh vực nào) nhằm điều chỉnh $\mathrm{CĐR}$ và $\mathrm{CTĐT} \mathrm{để} \mathrm{cá} \mathrm{thể} \mathrm{hóa} \mathrm{việc} \mathrm{học} \mathrm{tập} \mathrm{những} \mathrm{năm} \mathrm{cuối} \mathrm{đáp}$ ứng nhu cầu chuyển đổi nghề nghiệp của một số đông người học.

- Cần đáp ứng đề xuất về việc thành lập các nhóm nghiên cứu SV nghiên cứu khoa học.

- Cần tiến hành đối sánh mức độ hài lòng của các bên liên quan đối với CTĐT của nhà trường với các $\mathrm{CT} \mathrm{CT}$ tương đương trong và ngoài nước.

- Cần tiến hành đối sánh, phân tích, đánh giá các kết quả phản hồi từ các khảo sát của các bên liên quan để có thể có được những căn cứ xác đáng lập kế hoạch cải tiến chất lượng, đào tạo đáp ứng nhu cầu của xã hội và hội nhập quốc tế.

- Tóm lại, có thể nói việc áp dụng CDIO trong giai đoạn vừa qua đã có đóng góp tích cực trong quá trình xây dựng $\mathrm{CĐR}$ của $\mathrm{CT} \mathrm{TT}$, từ đó thiết kế chương trình và kế hoạch đào tạo tích hợp kiến thức và kỹ năng hình thành năng lực theo nhu cầu xã hội cho người học.

\section{Tài liệu tham khảo}

[1] Binh Thanh Phan, Minh Quang Le, Nhut Tan Ho, Trinh Minh Thi Doan, Hong Thi Tran, Long Tien Vu, Loc Huu Nguyen, Bac Hoai Le.. (2010) Development of a Model Framework for CDIO Implementation in Vietnam, Proceedings of the 6 the International CDIO Conference, École Polytechnique, Montréal, Canada, June 15-18, 2010.

[2] Hồ Thị Lan Hương, Nguyễn Xuân Huy, Đinh Thị Thanh Huyền, Đào Duy Lâm, Trần Văn Như, Nguyễn Đình Thạo, Nguyễn Cao Ý, Trần Hoài Trung. Hướng dẫn xây dựng chương trình đào tạo, phương pháp giảng dạy, kiểm tra - đánh giá theo CDIO (Dự thảo). Trường Đại học Giao Thông Vận Tải, 2020. 101 Tr.

[3] Hướng dẫn các tiêu chuẩn CDIO: Đại học Quốc gia Hà Nội, Đại học Quốc gia TP. HCM, Đại học Thủ Dầu Một, Đại học Vinh, Đại học Thủy Lợi.

[4] Tài liệu CDIO, Đại học Singapor Polytechnic.

[5] E.Crawley, J.Malmqvist, S.Ostlund, D.Brodeur. The CDIO Approach - Rethinking Engineering Education, Springer, 2007.

[6] Bộ Giáo dục và Đào tạo. Công văn số 4925/BGDĐT-GDĐH ngày 25 tháng 10 năm 2018, Bộ Giáo dục và Đạo tạo đã có chỉ đạo về việc hợp tác đổi mới chương trình đào tạo theo tiệp cận CDIO. 2018.

[7] Báo cáo triển khai áp dụng mô hình CDIO, 8/2009, báo cáo của khoa Cơ khí trường Đại học Bách khoa TP. Hồ Chí Minh.

[8] Nguyễn Hữu Lộc, Phạm Công Bằng \& Lê Ngọc Quỳnh Lam (2014).Chương trình đào tạo tích hợp: Từ thiết kế đến vận hành. NXB: ĐHQGHCM

[9] Cao Mạnh Tuấn, 7/2010, Tiếp cận CDIO để Chương trình đào $t$ ạo hiệu quả, báo Giáo dục \& Thời đại. 
[10] Lê Xuân Thọ, 2011, Tìm hiểu tình hình nghiên cứu "Ửng dụngphương pháp tiếp cận CDIO trong việc xây dựng chương trình đào tạo" ở một số trường Đại học ở Hà Nội và TP. Hồ Chí Minh.

[11] Nguyễn Hữu Cương. Phân biệt 3 mô hình đảm bảo chất lượng giáo dục đại học: Kiểm định chất lượng, đánh giá chất lượng và kiểm toán chất lượng. Tạp chí Khoa học ĐHQGHN: Nghiên cứu Giáo dục, Tập 33, Số 1 (2017), 91-96.

[12] Nguyễn Hữu Lộc, Phạm Công Bằng \& Lê Ngọc Quỳnh Lam (2014).Chương trình đào tạo tích hợp: Từ thiết kế đến vận hành. NXB: ĐHQGHCM.

[13] Nguyen, N. V., Pham, Y. N., Truong, H. K. (2015). CDIO Adaptation to International Business Program at University of Economics and Law-VNU-HCM. CDIO Implementation Project Report. Ho Chi Minh City: Vietnam National University.

[14] Khoa Báo chí và Truyền thông (BCTT) (2016) Báo cáo tự đánh giá áp dụng CDIO cho CTĐT Báo chí và Truyền thông tại Trường ĐH KHXH\&NV. Đề án CDIO, 7/2016. ĐHQG-HCM.

[15] Đoàn Thị Minh Trinh, Nguyễn Hội Nghĩa, Nguyễn Quốc Chính, Ngô Đình Thành, Mai Thanh Thủy, Đoàn Ngọc Khiêm, Nguyễn Thị Biên, Trần Văn Đồng, Lê Thanh Lực. Kết quả, kinh nghiệm triển khai và áp dụng CDIO cho các ngành kỹ thuật, phi kỹ thuật. Đại học Quốc gia TP. HCM (ĐHQG-HCM).

[16] Đại học Mỏ - Địa chất. Tài liệu tập huấn phỏng vấn đảm bảo chất lượng chương trình đào tạo. Theo tiêu chuẩn đánh giá chất lượng chương trình đào tạo của Bộ Giáo dục và Đào tạo. Trường Đại học Mỏ - Địa chất, Hà Nội, 2020. 58 trang (Tài liệu lưu hành nội bộ).

[17] Đại học Mỏ - Địa chất. Báo cáo hội nghị đại biểu cán bộ, viên chức lần thứ 47. Trường Đại học Mỏ - Địa chất, Hà Nội, 11/2020. 66 trang (Tài liệu lưu hành nội bộ).

[18] Đại học Xây dựng. Tập huấn CDIO mở rộng, tháng 10/2020. TF-SP TVET (General) Specialist Programme in Hanoi, Vietnam. Hà Nội, 26-30/10/2020.

[19] Trung tâm Kiểm định Chất lượng Giáo dục - Trường Đại học Vinh. Báo cáo đánh giá ngoài chương trình đào tạo kỹ sư ngành Kỹ thuật Xây dựng - Trường Đại học Mỏ - Địa chất. Theo tiêu chuẩn đánh giá chất lượng chương trình đào tạo của Bộ Giáo dục và Đào tạo (Giai đoạn đánh giá: 2014-2019). Nghệ An, tháng 10/2020. 108 Tr. (Lưu hành nội bộ). 